\title{
Effectiveness and characteristics of interventions to improve work participation in adults with chronic physical conditions: a systematic review
}

Joan A. C. Verhoef, Marjolijn I. Bal, Pepijn D. D. M. Roelofs, Jeroen A. J. Borghouts, Marij E. Roebroeck \& Harald S. Miedema

To cite this article: Joan A. C. Verhoef, Marjolijn I. Bal , Pepijn D. D. M. Roelofs, Jeroen A. J. Borghouts , Marij E. Roebroeck \& Harald S. Miedema (2020): Effectiveness and characteristics of interventions to improve work participation in adults with chronic physical conditions: a systematic review, Disability and Rehabilitation, DOI: 10.1080/09638288.2020.1788180

To link to this article: https://doi.org/10.1080/09638288.2020.1788180

\section{里 Published online: 20 Jul 2020.}

Submit your article to this journal $\pi$

Џ Article views: 10

Q View related articles $₫$

View Crossmark data $₫$ 


\title{
Effectiveness and characteristics of interventions to improve work participation in adults with chronic physical conditions: a systematic review
}

\author{
Joan A. C. Verhoef ${ }^{a, b}$, Marjolijn I. Bal ${ }^{a, b}$, Pepijn D. D. M. Roelofs ${ }^{a}$, Jeroen A. J. Borghouts ${ }^{c}$, Marij E. Roebroeck ${ }^{b, d}$ \\ and Harald S. Miedema ${ }^{a}$

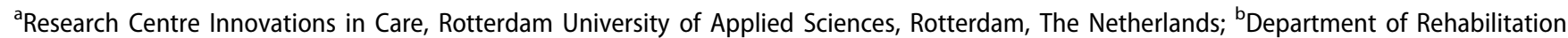

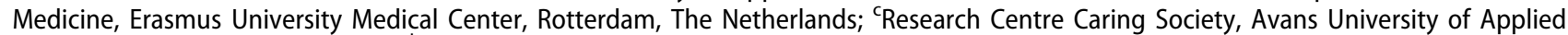

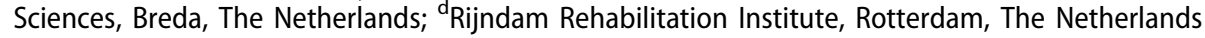

\begin{abstract}
Purpose: Chronic physical conditions often negatively affect work participation. The objective of this systematic review is to investigate the effectiveness and characteristics of vocational rehabilitation interventions for people with a chronic physical condition.

Methods: Searches in five databases up to April 2020 identified 30 studies meeting our inclusion criteria. Two reviewers independently assessed and extracted data. The Grading of Recommendation, Assessment, Development and Evaluation (GRADE) framework was used to evaluate quality of evidence for three outcome measures related to work participation.

Results: All vocational rehabilitation interventions consisted of multiple components, but their characteristics varied widely. Analysis of 22 trials yielded a moderate positive effect with moderate certainty of interventions on work status; analysis of five trials with low risk of bias showed a large positive effect with moderate certainty (risk ratio 1.33 and 1.57, respectively). In addition, in eight studies we found a moderate to small positive effect with low certainty on work attitude (standardized mean difference $=$ 0.59 or 0.38 , respectively). We found no effect on work productivity in nine studies.

Conclusion: The systematic review of the literature showed positive effects of vocational rehabilitation interventions on work status and on work attitude; we found no effect on work productivity.
\end{abstract}

> IMPLICATIONS FOR REHABILITATION

- In rehabilitation, addressing work participation of persons with a chronic physical condition using targeted interventions is beneficial to improve or sustain work participation, irrespective of the intervention characteristics and diagnosis.

- Interventions that include multiple components and offer individual support, whether or not combined with group sessions, are likely to be more effective in improving work participation in persons with a chronic physical condition.

- The overview of vocational interventions in this systematic review may assist healthcare professionals in making informed decisions as to which intervention to provide.

- Vocational rehabilitation, as well as studies on work participation in chronic disease, should include a long follow-up period to explore if work participation is sustainable and contributes to health and wellbeing.
ARTICLE HISTORY

Received 4 December 2019

Revised 22 June 2020

Accepted 23 June 2020

\section{KEYWORDS}

Vocational rehabilitation; chronic disease; employment; evidencebased practice; systematic review

\section{Introduction}

Chronic physical conditions often result in disability, such as pain and physical limitations, and restrictions in daily activities and participation in society. Participation restrictions frequently include temporary or permanent health-related problems in work participation, such as (involuntary) part-time employment, difficulty meeting work demands (e.g. work hours, work pace), difficulty in performing work tasks, balancing work and home life, as well as dealing with sick leave, and job loss or unemployment [1-6]. Due to the increasing number of people with a chronic physical condition and their problems with employment, their work participation is a growing concern in society $[1,6]$.

About $30 \%$ of employees with a chronic condition experiences problems with employment related to their condition [3]. Despite disease-specific differences, there are generic characteristics that can be considered common consequences of a chronic physical condition that hamper work participation, such as pain, fatigue and functional disabilities, variability of symptoms, an unpredictable course of symptoms, and long-lasting impact of consequences $[3,5-8]$. As a result, people with chronic physical conditions may face many similar challenges and adaptive tasks to participate in work [9]. In addition, a systematic review found that most of the factors associated with work participation of workers with a chronic physical condition are independent of the diagnosis [10]. Therefore, the use of a generic approach to improve the work participation of persons with a chronic physical condition might be appropriate. However, an overview of interventions and evidence on the effectiveness of interventions to enhance work 
participation of people with chronic physical conditions, irrespective of diagnosis, is lacking.

The current systematic review investigates the effectiveness and characteristics of vocational rehabilitation interventions for people with a chronic physical condition. For this study, chronic back pain was excluded because vocational interventions for patients with chronic back pain have been systematically reviewed and published [11-14].

\section{Methods}

A systematic review of the literature was performed: such reviews seek to systematically search for, appraise and synthesize research evidence [15]. This type of review allows to explore the effectiveness and intervention characteristics. The study protocol was not registered and has not previously been published.

\section{Search strategy}

A systematic extensive electronic search was conducted in the databases MEDLINE, CINAHL, Cochrane controlled trials register, Embase and PsycINFO up to April 2020. The search strategy was developed based on literature [16,17], group discussions among the authors, and preliminary searches to inform the strategy. The final search strategy employed variations and Boolean connections (AND, OR, NOT) of MeSH terms, subject headings and keywords related to chronic physical conditions, vocational rehabilitation, and work participation. In addition, we used the search strategy for randomized controlled trials and controlled clinical trials as recommended by the Cochrane collaboration [18]. The search strategy was adapted according to the particular database, using database thesauruses to identify relevant variations of these terms. The search strategy used in Medline is presented in Box 1. In addition, the reference lists of the identified original papers were checked for additional relevant studies.

Box 1. Search strategy (Medline)

((((Clinical trial[pt] OR randomized[tiab] OR placebo[tiab] OR clinical trials[mh] OR randomly[tiab] OR trial[ti]) NOT (animals[mh]))) AND (program* OR training OR education OR rehabilitation OR multidisciplinary OR therapy)) AND ("Work"[Mesh] OR "Employment"[Mesh] OR "Employment, Supported"[Mesh] OR "Occupations"[Mesh] OR job OR employment OR vocation)) AND (("Chronic Disease"[Mesh] OR "Disabled Persons"[Mesh] OR chronic OR disability or disabilities) NOT (mental or mentally or psychiatric)

\section{Study selection}

Retrieved records $(n=13,156)$ were imported into Endnote and duplicates were removed $(n=3465)$. Inclusion criteria for this review were: (i) population: working-age adults (18-65 years) with a chronic physical condition, other than chronic back pain, lasting $\geq 3$ months or that can be categorized as long-lasting based on disease characteristics (e.g. rheumatoid arthritis), (ii) Intervention: studies focusing on vocational rehabilitation interventions containing specific elements to improve work participation (excluding surgery, medication), (iii) Comparison: no vocational intervention (usual care, waiting list), (iv) outcome: work participation (v) original controlled trials in the English language and peer-reviewed.

Based upon title and abstract, three authors (JV, MB, PR) independently screened the articles for eligibility and excluded the studies that clearly did not meet one or more inclusion criteria $(n=9429)$. Full-text copies of all other articles $(n=119)$ were obtained and two authors (JV, MB) independently decided on the inclusion of these studies, based upon full text. At all stages of selection, disagreements in the independent decisions were resolved by discussion until consensus was reached. If both reviewers did not reach consensus, a third author was consulted (HM). The selection process and reasons for exclusion are shown in Figure 1.

\section{Data extraction}

Two reviewers (JV, MB) extracted data on study design, study sample, characteristics and content of intervention [format (individual, group, combined), approach and professionals (mono- or multidisciplinary) duration (short, moderate and long) and intensity (low and high), and focus (vocational, cognitive-behavioural or physical)], outcome measures and study results using a predesigned data extraction form. Duration of interventions was categorized as short ( $<10$ weeks), moderate $(10-16$ weeks) or long ( $>16$ weeks), based on median ( 10 weeks) and mean ( 16 weeks) values of duration of interventions, and intensity as low $(\leq 40 \mathrm{~h}$ in total) or high $(>40 \mathrm{~h})$, based on mean number of hrs. The focus of interventions was characterized as vocational, cognitive-behavioural or physical, based on the functional domain that was primarily targeted to improve work participation.

Outcome measures were inductively derived from the data, namely:

1. Work status, reported as dichotomous outcome (yes/no) presenting the proportion of the study sample achieving return to work, employment or job maintenance;

2. Work productivity, reported as continuous outcome presenting work productivity (hours per week worked) or duration of sick leave;

3. Work attitude, reported as continuous outcome presenting scores on work readiness (action to find a job), employment activities, employability or self-efficacy at work.

Two reviewers (JV, MB) independently assigned the study outcomes to these three outcome measures. Other outcomes from the selected studies were not included in this review.

\section{Methodological quality assessment}

For each of the 30 included studies, two reviewers (JV and MB) independently assessed the methodological quality using the Effective Public Health Practice Project Quality Assessment Tool (EPHPP) for Quantitative Studies (https://merst.ca/wp-content/ uploads/2018/02/quality-assessment-tool_2010.pdf). This tool assesses six domains or potential sources of Risk of Bias: (1) selection bias; (2) study design; (3) confounders; (4) blinding; (5) data collection method; and (6) withdrawals and dropouts. We decided to use the EPHPP tool rather than the Cochrane Collaboration Risk of Bias Tool, because the EPHPP tool was developed for use with various intervention study designs (not only randomized controlled trials), which we intended to include. The scoring of the EPHPP is based on objective guidelines [19]. Consistent with the EPHPP Quality assessment tool dictionary, each domain was rated as strong, moderate or weak and the methodological quality of the study was rated as strong when no domain was rated as weak, moderate if one domain was rated as weak, and low if two or more domains were rated as weak. Any disagreement about the methodological quality was resolved by discussion until consensus was reached. 


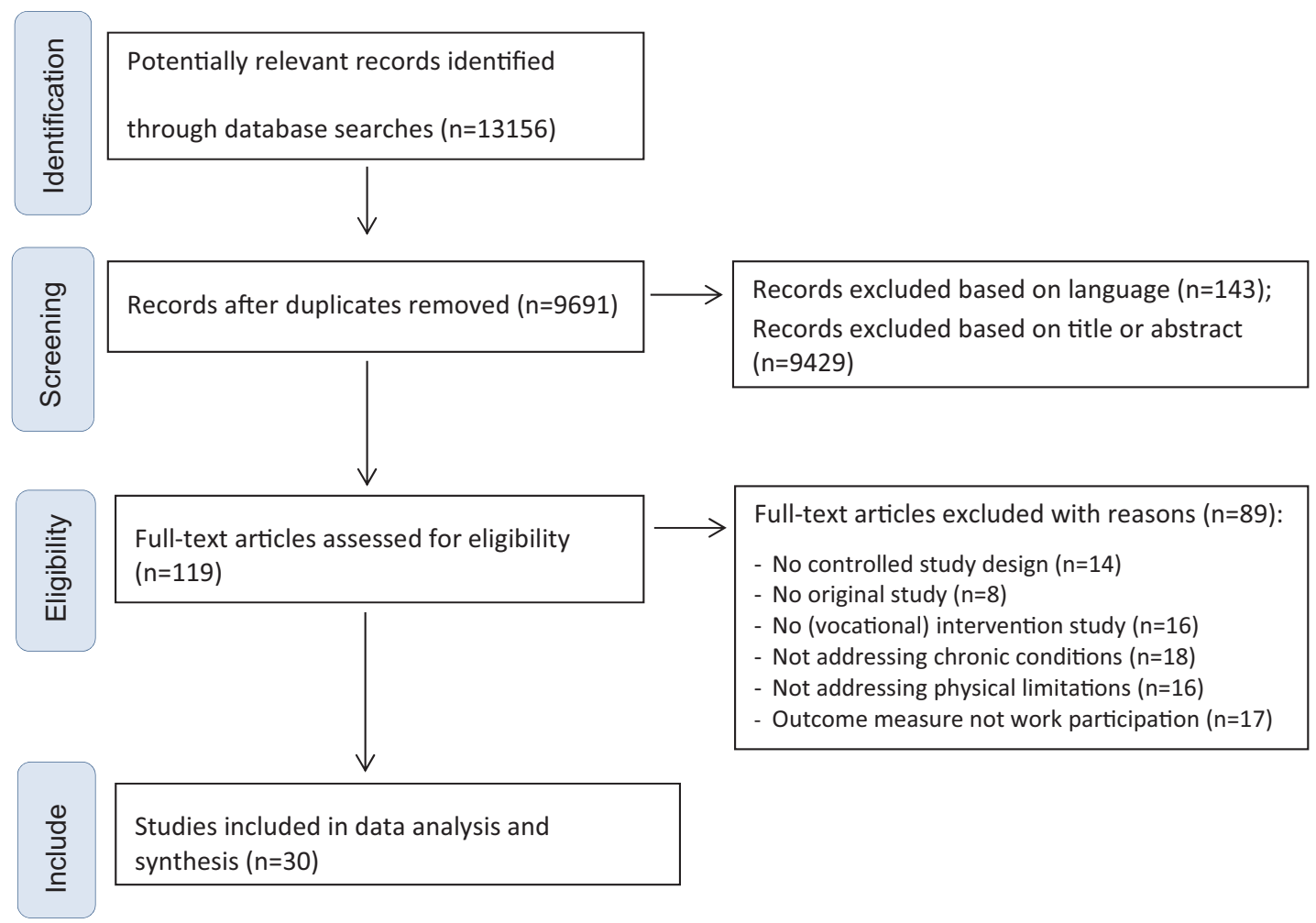

Figure 1. Flowchart of identification and selection of studies.

Table 1. Methodological quality rating of the included studies using the Effective Public Health Practice Project Quality Assessment Tool.

\begin{tabular}{|c|c|c|c|c|c|c|c|}
\hline Study & $\begin{array}{l}\text { Selection } \\
\text { bias }\end{array}$ & $\begin{array}{l}\text { Study design } \\
\text { (Allocation bias) }\end{array}$ & Confounders & $\begin{array}{c}\text { Blinding } \\
\text { (detection bias) }\end{array}$ & $\begin{array}{l}\text { Data collection } \\
\text { methods }\end{array}$ & $\begin{array}{l}\text { Withdrawals and } \\
\text { drop-outs } \\
\text { (attrition bias) }\end{array}$ & Rating \\
\hline Hutting et al. [22] & $M$ & $S$ & $S$ & $M$ & $\mathrm{~S}$ & $M$ & Strong \\
\hline Li et al. [40] & M & $\mathrm{s}$ & $\mathrm{s}$ & $\mathrm{s}$ & $\mathrm{s}$ & $\mathrm{s}$ & Strong \\
\hline Li-Tsang et al. [41] & $\mathrm{s}$ & $\mathrm{s}$ & $\mathrm{s}$ & $\mathrm{S}$ & $\mathrm{S}$ & $\mathrm{S}$ & Strong \\
\hline Marhold et al. [43] & $\mathrm{s}$ & $S$ & $S$ & M & $S$ & $S$ & Strong \\
\hline Meyer et al. [54] & s & $\mathrm{s}$ & $\mathrm{s}$ & s & M & $\mathrm{s}$ & Strong \\
\hline Ntsiea et al. [46] & $\mathrm{s}$ & $\mathrm{s}$ & $\mathrm{S}$ & M & $\mathrm{s}$ & $\mathrm{S}$ & Strong \\
\hline Sullivan et al. [50] & M & M & $\mathrm{s}$ & M & M & $\mathrm{S}$ & Strong \\
\hline Trexler et al. [51] & M & $\mathrm{s}$ & $\mathrm{s}$ & M & $\mathrm{s}$ & $\mathrm{s}$ & Strong \\
\hline Allaire et al. [30] & W & $\mathrm{S}$ & $\mathrm{S}$ & M & M & M & Moderate \\
\hline Cheng and Hung [33] & W & $\mathrm{s}$ & $\mathrm{s}$ & M & M & $\mathrm{s}$ & Moderate \\
\hline De Buck et al. [34] & M & $\mathrm{s}$ & $\mathrm{S}$ & M & W & $\mathrm{S}$ & Moderate \\
\hline Ipsen et al. [38] & M & $S$ & $S$ & S & $\mathrm{S}$ & W & Moderate \\
\hline Kendall and Thompson [39] & M & $\mathrm{s}$ & W & $\mathrm{S}$ & $\mathrm{s}$ & M & Moderate \\
\hline Keysor et al. [56] & W & $S$ & $\mathrm{~S}$ & $S$ & $S$ & $\mathrm{~S}$ & Moderate \\
\hline Macedo et al. [42] & M & $\mathrm{s}$ & $\mathrm{s}$ & W & $\mathrm{s}$ & $\mathrm{S}$ & Moderate \\
\hline Salazar et al. [48] & M & $\mathrm{s}$ & $\mathrm{S}$ & W & M & $\mathrm{S}$ & Moderate \\
\hline Skouen et al. [49] & $M$ & $\mathrm{~s}$ & W & $M$ & $\mathrm{~s}$ & $\mathrm{~s}$ & Moderate \\
\hline Anderson et al. [31] & W & $\mathrm{s}$ & W & M & $\mathrm{s}$ & W & Weak \\
\hline Brattberg et al. [32] & W & $\mathrm{S}$ & $\mathrm{S}$ & M & W & $\mathrm{s}$ & Weak \\
\hline Detaille et al. [35] & W & $\mathrm{s}$ & $\mathrm{s}$ & M & W & M & Weak \\
\hline Dorstyn et al. [57] & W & S & $S$ & M & W & M & Weak \\
\hline Feuerstein et al. [36] & $M$ & M & W & $M$ & $M$ & W & Weak \\
\hline Haffey et al. [37] & $\mathrm{S}$ & M & $\mathrm{s}$ & W & W & W & Weak \\
\hline Hammond et al. [55] & W & $\mathrm{s}$ & W & M & M & M & Weak \\
\hline Marnetoft and Selander [44] & M & M & $\mathrm{s}$ & M & W & W & Weak \\
\hline Martin et al. [23] & W & $\mathrm{S}$ & $S$ & M & W & W & Weak \\
\hline Niemeijer et al. [45] & W & $\mathrm{s}$ & $\mathrm{s}$ & W & $M$ & s & Weak \\
\hline Ottomanelli et al. [47] & W & $\mathrm{s}$ & W & W & W & $\mathrm{S}$ & Weak \\
\hline Van Vilsteren et al. [53] & W & $\mathrm{s}$ & $\mathrm{s}$ & W & $\mathrm{s}$ & $\mathrm{s}$ & Weak \\
\hline Varekamp et al. [52] & W & $\mathrm{s}$ & M & M & W & M & Weak \\
\hline
\end{tabular}




\section{Data analysis and synthesis}

A mixture of strategies was used for data analysis to accommodate the variety of interventions and studies.

First, the content and characteristics of interventions were described based on data-extraction.

Second, we explored effectiveness of interventions for each outcome measure separately. The estimated effects of all studies for each outcome were first visually displayed in forest plots using Review Manager (software version 5.3) $[18,20]$. A random effects model was applied to take into account the possible statistical heterogeneity of the studies. For the dichotomous outcome work status, the risk ratio (RR) was used to compare effect sizes $[18,21]$. For the continuous outcomes work productivity and work attitude the standardized mean difference (SMD) was used, since measurement scales differed across studies [21]. Data obtained at 12 months ( 52 weeks) follow-up were used for the analyses. Otherwise, the duration of follow-up in weeks was added to the study reference (for example: Macedo et al. 2009_26). In the case of missing data, authors were contacted to request additional information [22]. Studies lacking standard deviations (SD) of mean scores were not included in the forest plots [23].

Third, statistical pooling (meta-analysis) of the outcome measures work status, work productivity and work attitude was performed, for all studies that reported one (or more) of these specific outcome measures, as well as the subset of studies of which the methodological quality was rated as high. Statistical heterogeneity was assessed with $\mathrm{Chi}^{2}$ and $l^{2}$ statistics. The effect size of the dichotomous outcome measure work status was interpreted as high, when the RR was $\leq 0.50$ or $\geq 1.50$ and as moderate with an RR $>0.50$ but $\leq 0.75$ or $<1.50$ but $\geq 1.25$. Interpretation of the effect size of continuous outcome measures with SMD was based on Cohen's method [24]: small when SMD $>0.20$ (but $<0.50$ ), moderate when $\mathrm{SMD} \geq 0.50$ (but $<0.80$ ) and large when $\mathrm{SMD} \geq 0.80$.

Finally, we assessed the overall quality of the evidence for each outcome measure using the Grades of Recommendation, Assessment, Development and Evaluation Working Group (GRADE) approach [18,25-28]. Evidence of randomized controlled trials was rated as high, but could be rated down by one level (into moderate) or by two or three levels (to low or very low quality), with respect to each of five factors: (1) risk of bias: outcome of EPHPP-tool moderate or weak; (2) inconsistency: variability or heterogeneity in magnitude of effect among studies; (3) indirectness of evidence: indirect comparison of interventions within studies; (4) imprecision of results: for dichotomous outcomes full confidence intervals $(\mathrm{Cl})$ below 0.75 or above 1.25 or a number of participants of $\geq 300$; for continuous outcomes full $\mathrm{Cl}$ below or above the level of a predefined minimal important difference or number of participants $\geq 400$; (5) likeliness of publication bias: underestimation or overestimation of effect due to selective publication of studies. Publication bias was checked by constructing a funnel plot [29].

\section{Results}

\section{Study characteristics}

A total of 30 studies met our inclusion criteria for this systematic review [22,23,30-57] (see Figure 1). These studies addressed work participation in patients with various chronic physical conditions, such as musculoskeletal disorders and/or musculoskeletal pain $(n=13)$, rheumatic diseases $(n=6)$, traumatic brain injury $(n=5)$, mixed population of various chronic physical diseases $(n=3)$, spinal cord injury $(n=2)$ and human immunodeficiency virus (HIV) $(n=1)$.

Studies were published between 1991 and 2020 and conducted in various countries: the USA $(n=10)$, the Netherlands $(n=5)$, Hong Kong $(n=3)$, Sweden $(n=3)$, Norway $(n=2)$, United Kingdom $(n=2)$, Australia $(n=1)$, Canada $(n=1)$, New Zealand $(n=1)$, South Africa $(n=1)$ and Switzerland $(n=1)$.

\section{Methodological quality of the included studies}

The results of the methodological quality assessment are presented in Table 1: 8 studies were rated as high quality, 9 studies as moderate quality and 13 studies as low quality.

\section{Characteristics and content of interventions}

An overview of the characteristics of the included studies and interventions is presented in Table 2 . With regard to intervention format, 11 of 30 interventions (37\%) combined a group program and individual treatment, 13 interventions (43\%) only offered individual treatment and 6 interventions (20\%) only provided a group program (Tables 2 and 3).

Fifteen interventions (50\%) applied a monodisciplinary approach and 15 interventions (50\%) a multidisciplinary approach. In ten of the 15 multidisciplinary interventions (67\%), the team consisted of healthcare professionals only (for example: physician, physiotherapist, occupational therapist, psychologist); four interventions (27\%) included also vocational professionals, such as a vocational counsellor or job coach. One team consisted of vocational professionals only. Fourteen interventions (47\%) had a short duration, lasting <10 weeks; five (17\%) with a high intensity $(>40 \mathrm{~h}$ in total) and nine (30\%) with a low intensity. Eight interventions (27\%) had a moderate duration of $10-16$ weeks, two (7\%) with a high and six (20\%) with a low intensity. Another eight interventions (27\%) had a long duration, lasting $\geq 16$ weeks, all with a low intensity.

All 30 interventions consisted of multiple treatment components, with a focus on vocational, (cognitive-)behavioural or physical functioning. Interventions primarily targeting vocational functioning to improve work participation ( $n=16 ; 53 \%$ ), included job searching, job interview skills, specific work training, job placement, vocational counselling, or work place visits. Interventions primarily targeting (cognitive-) behavioural change ( $n=9 ; 30 \%$ ), included coping strategies, problem solving, goal setting, cognitive skills, communication skills, stress management or empowerment. Interventions targeting physical functioning to improve work participation $(n=5 ; 17 \%)$, included exercise training, skills training, graded activity or work hardening.

\section{Effectiveness of interventions on work participation}

A summary of the effectiveness and characteristics of interventions, related to the three outcome measures, is presented in Table 3. Twenty-two studies addressed one of the three outcome measures of work participation, seven studies addressed two, and one study addressed all three outcomes. In total, the 30 studies addressed 39 outcomes.

Below we describe the effectiveness for each of the three outcomes; these results are visualized in Figures 2-4.

\section{Effects on work status $(n=22)$}

Twenty-two studies measured the dichotomous difference in work status, such as return to work; (competitive, paid) employment, 
VOCATIONAL REHABILITATION IN CHRONIC CONDITIONS -5

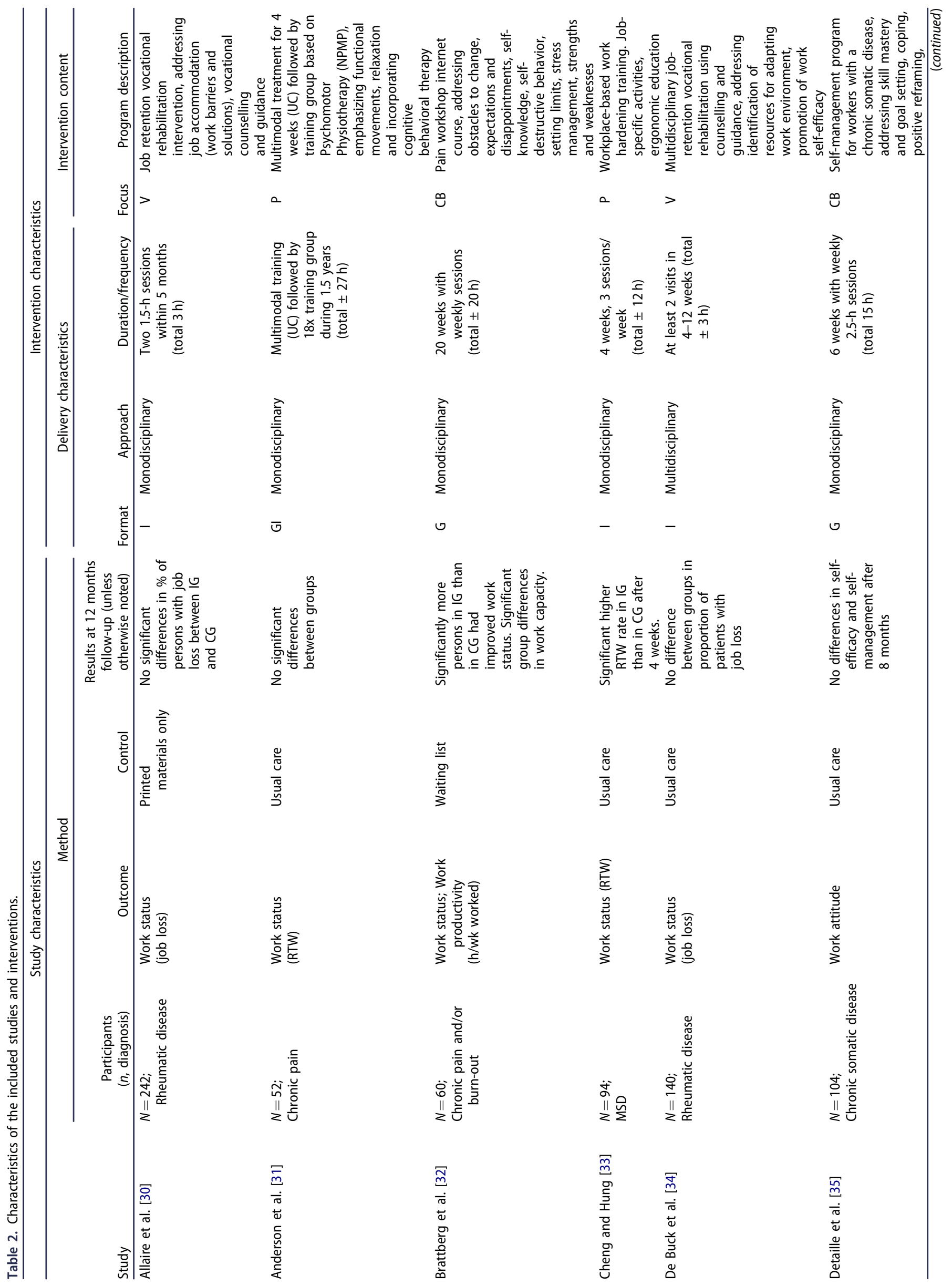


6 J. A. C. verhoef et Al.

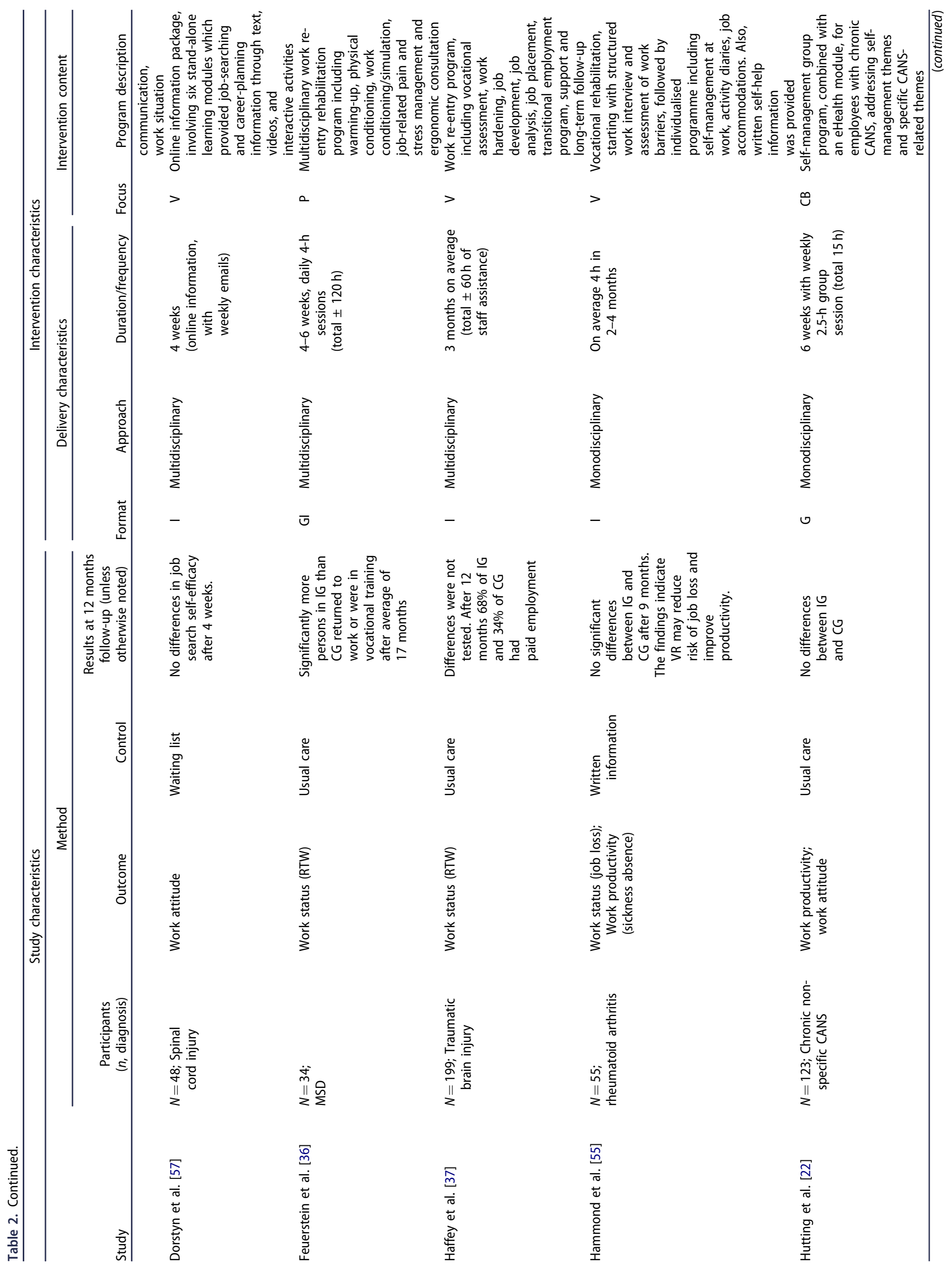




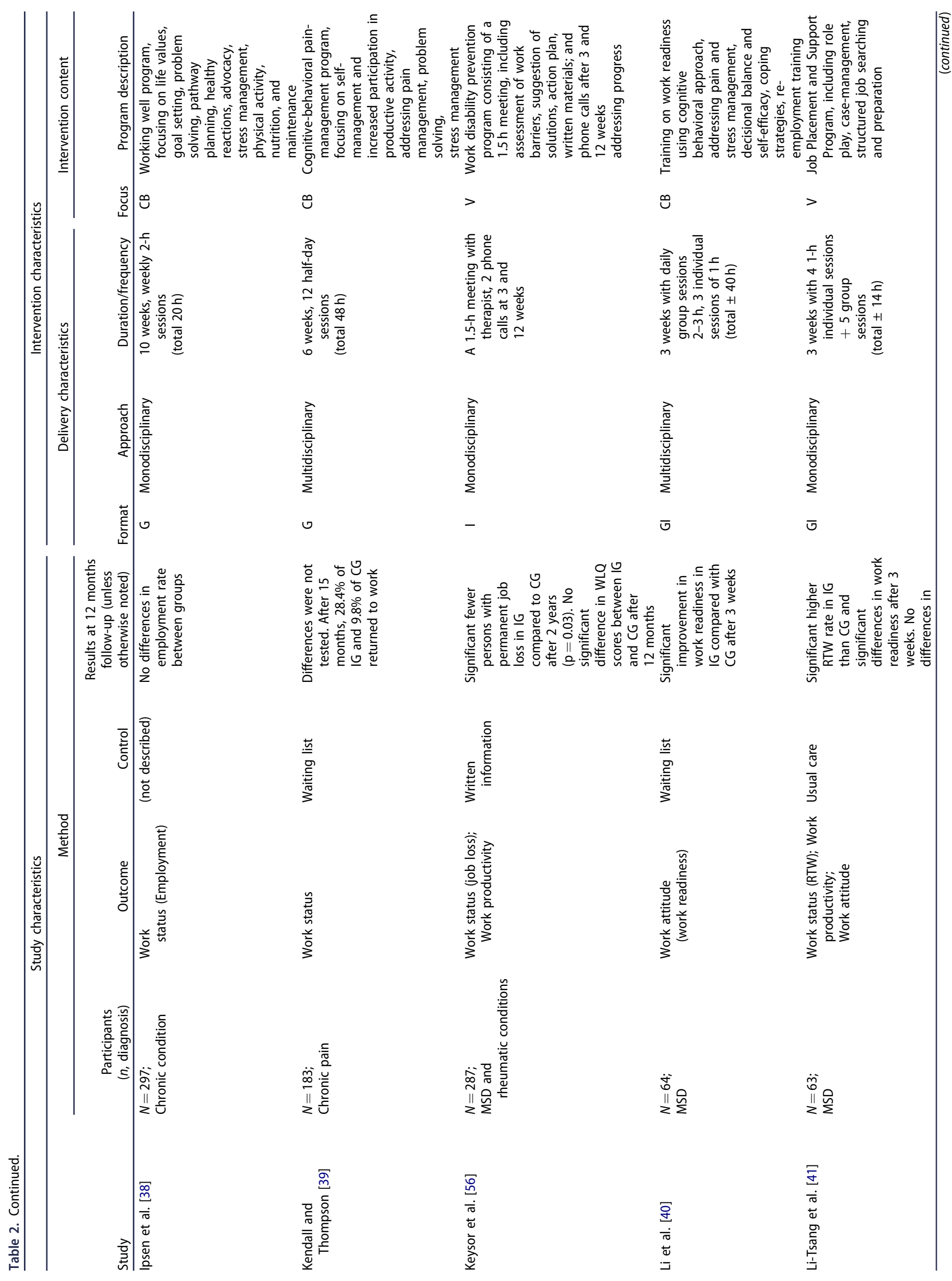


$8-$ J. A. C. VerHOEF Et AL.

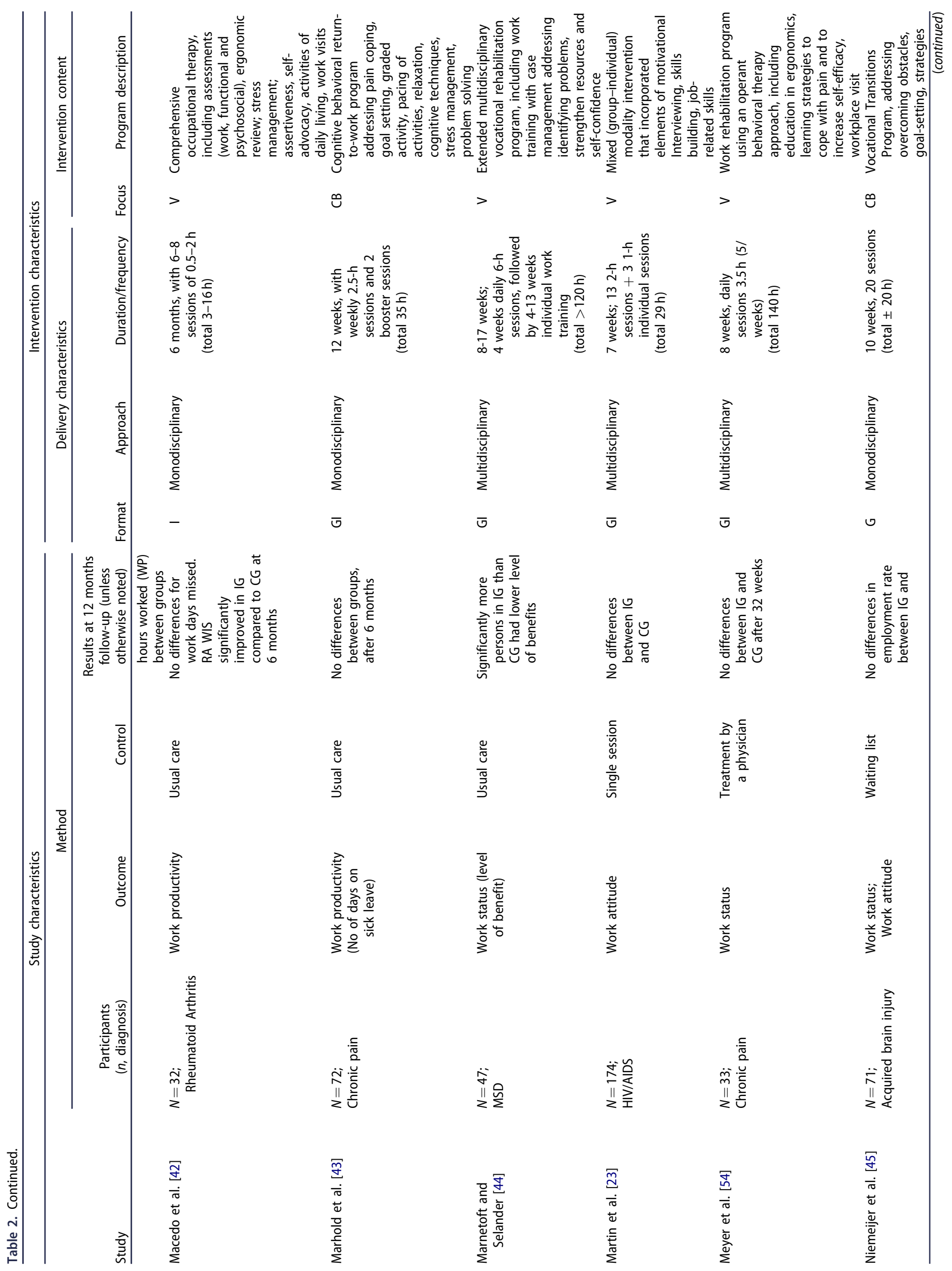




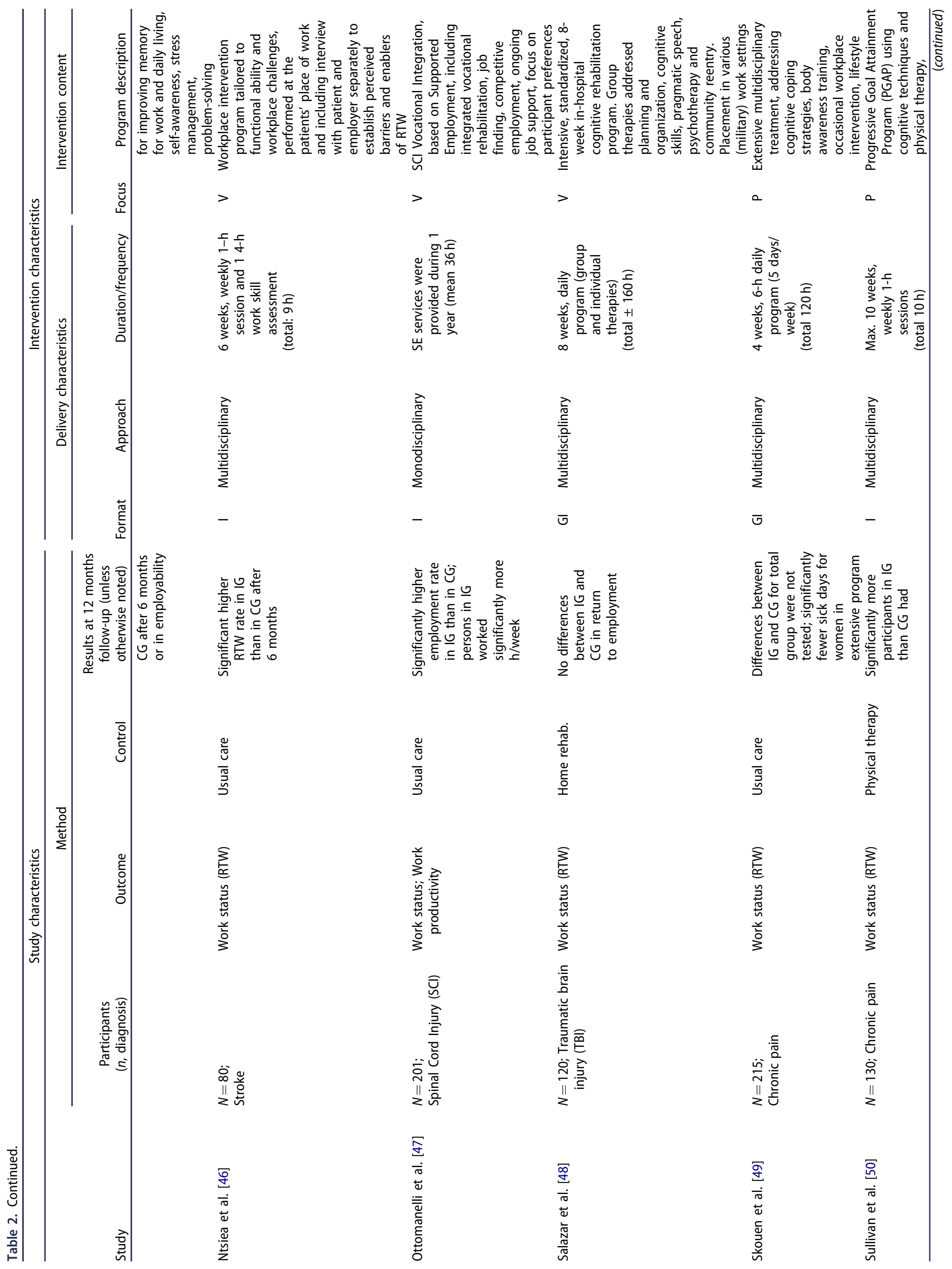


$10-$ J. A. C. Verhoef et AL.

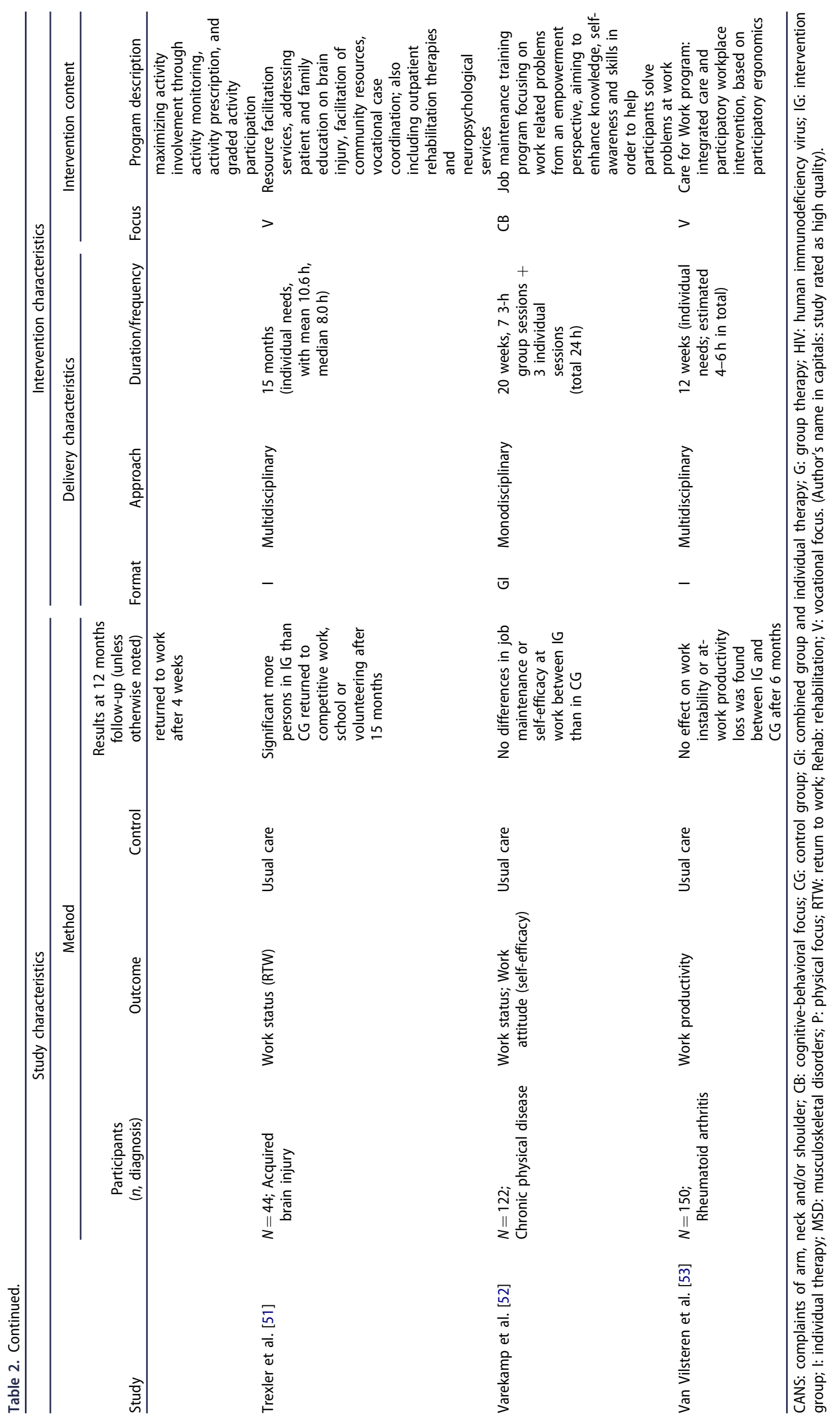


Table 3. Characteristics and effectiveness of the interventions.

\begin{tabular}{|c|c|c|c|c|c|c|}
\hline & \multirow[b]{2}{*}{$\begin{array}{c}\text { Number of studies } \\
(n=30)\end{array}$} & \multicolumn{3}{|c|}{ Outcome $^{\mathrm{a}}$} & \multirow[b]{2}{*}{$\begin{array}{l}\text { Number of studies with } \\
\text { significant effect }(\mathrm{HQ})^{\mathrm{b}} \\
(n=12(5))\end{array}$} & \multirow{2}{*}{$\begin{array}{c}\text { Number } \\
\text { of studies with lack } \\
\text { of effect }(\mathrm{HQ})^{\mathrm{b}} \\
(n=18(3))\end{array}$} \\
\hline & & $\begin{array}{l}\text { Work status } \\
\quad(n=22)\end{array}$ & $\begin{array}{l}\text { Work productivity } \\
\qquad(n=9)\end{array}$ & $\begin{array}{l}\text { Work attitude } \\
\qquad(n=8)\end{array}$ & & \\
\hline \multicolumn{7}{|l|}{ Form } \\
\hline Group + individual & 11 & 8 & 3 & 4 & $5(2)$ & $6(2)$ \\
\hline Individual & 13 & 10 & 4 & 1 & $6(3)$ & $7(-)$ \\
\hline Group & 6 & 4 & 2 & 3 & $1(-)$ & $5(1)$ \\
\hline \multicolumn{7}{|l|}{ Approach } \\
\hline Multidisciplinary & 15 & 11 & 2 & 3 & $6(4)$ & $9(1)$ \\
\hline Monodisciplinary & 15 & 11 & 7 & 5 & $6(1)$ & $9(2)$ \\
\hline \multicolumn{7}{|l|}{ Duration and intensity } \\
\hline \multicolumn{7}{|l|}{ Short } \\
\hline High & 5 & 5 & - & - & $1(-)$ & $4(1)$ \\
\hline Low & 9 & 4 & 2 & 6 & $4(3)$ & $5(1)$ \\
\hline \multicolumn{7}{|l|}{ Moderate } \\
\hline High & 2 & 2 & 1 & - & $1(1)$ & $1(-)$ \\
\hline Low & 6 & 5 & 2 & 1 & $2(1)$ & $4(-)$ \\
\hline \multicolumn{7}{|l|}{ Long } \\
\hline Low & 8 & 6 & 4 & 1 & $4(1)$ & $4(1)$ \\
\hline \multicolumn{7}{|l|}{ Focus of program } \\
\hline Vocational & 16 & 12 & 6 & 3 & $6(3)$ & $10(1)$ \\
\hline Cognitive-behavioral & 9 & 5 & 3 & 5 & $3(1)$ & $6(2)$ \\
\hline Physical & 5 & 5 & - & - & $3(1)$ & $2(-)$ \\
\hline
\end{tabular}

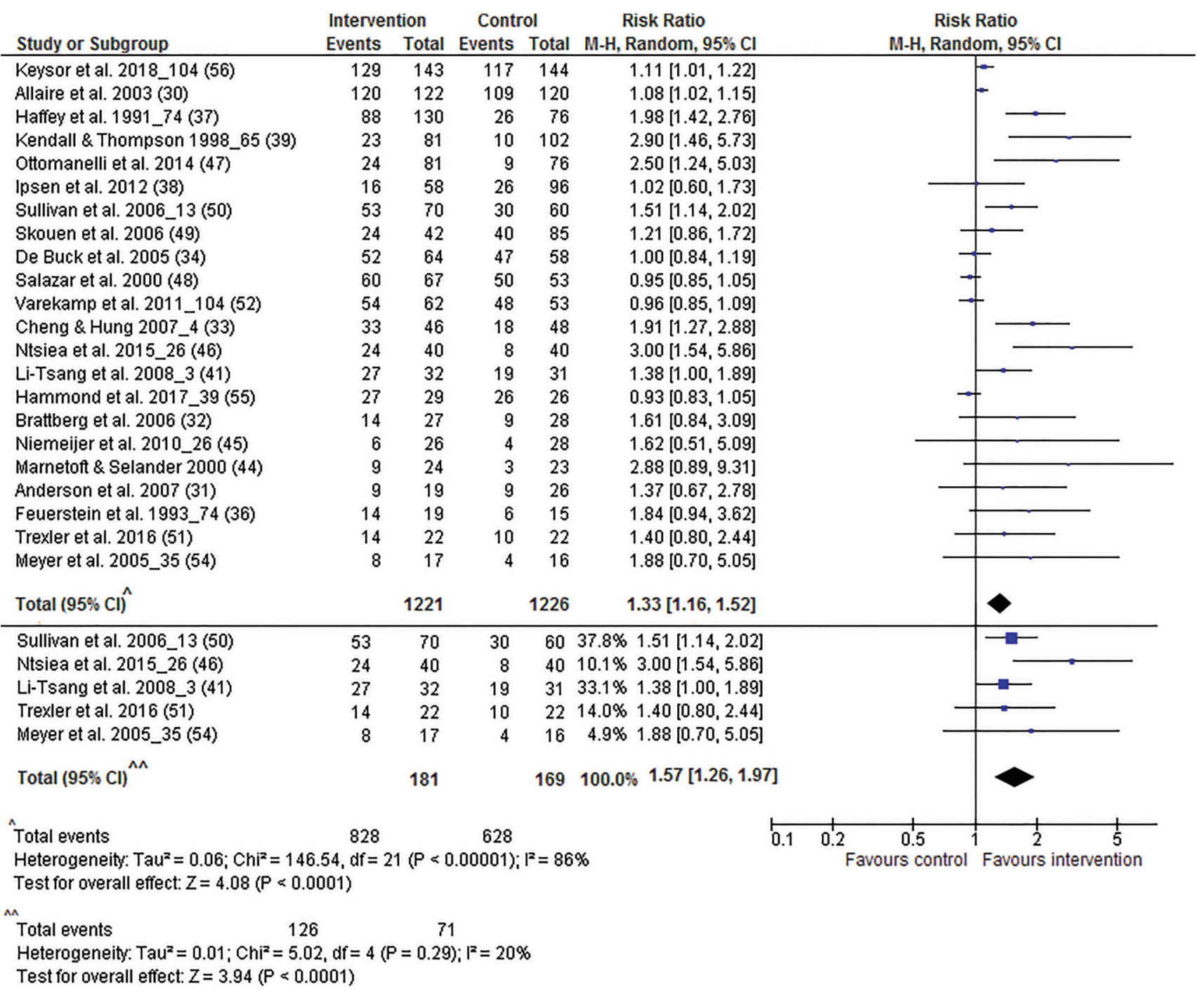

Figure 2. Effectiveness of interventions on outcome: work status in all studies and high-quality studies (ordered by sample size). 


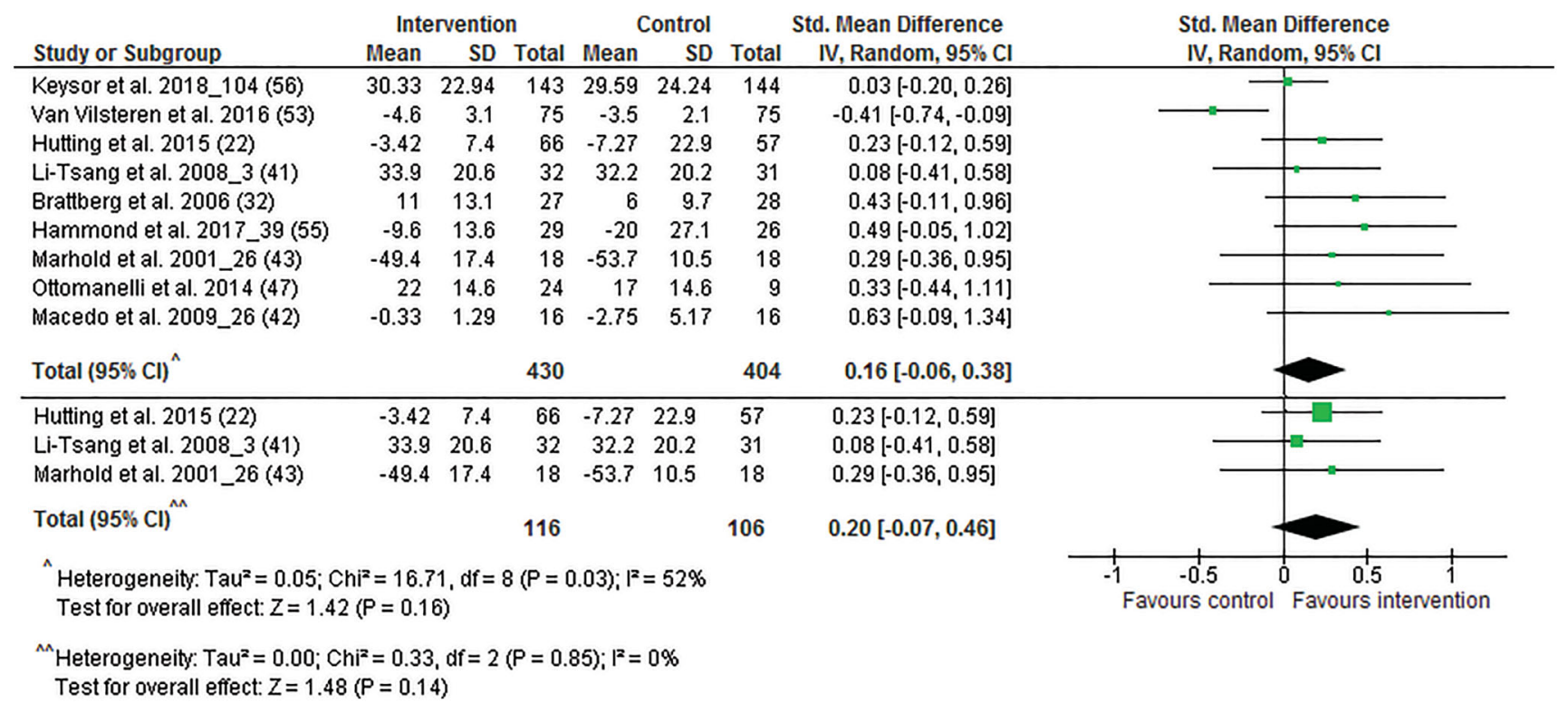

Figure 3. Effectiveness of interventions on outcome: work productivity in all studies and high-quality-studies (ordered by sample size).

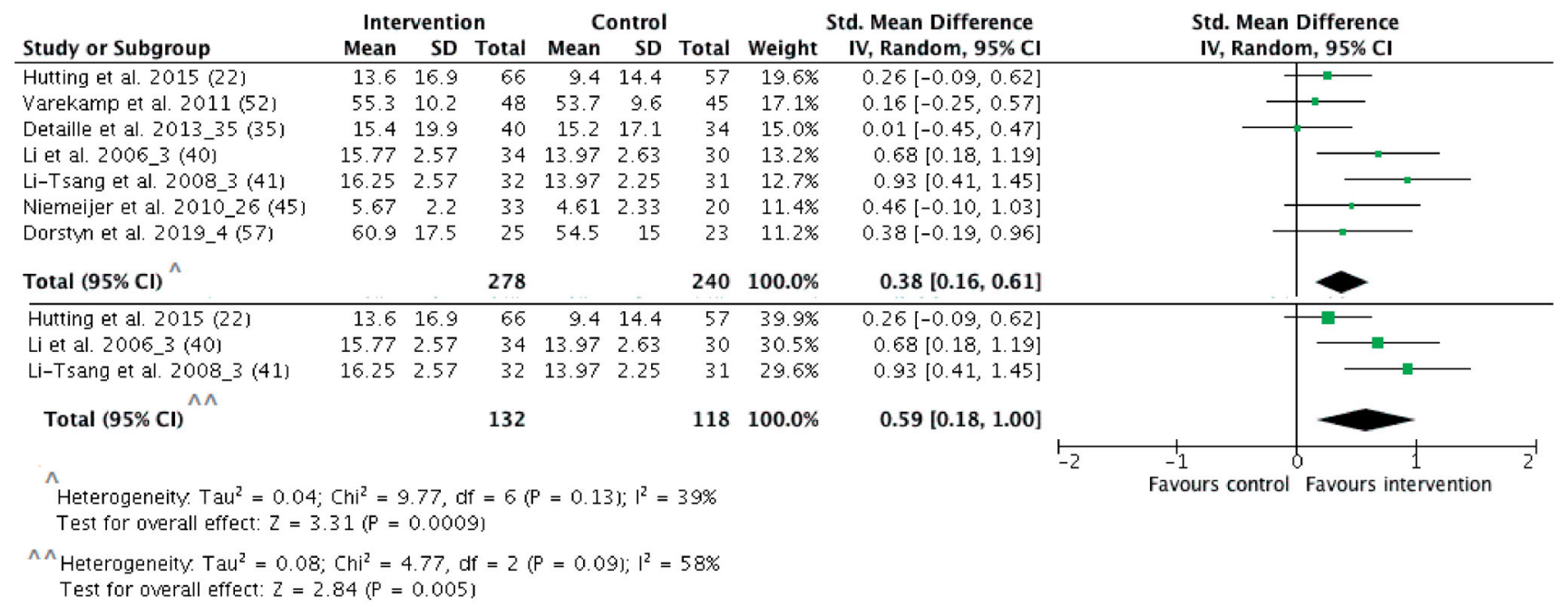

Figure 4. Effectiveness of interventions on outcome: work attitude in all studies and high-quality studies (ordered by sample size).

Table 4. Evidence profile for the outcomes work status, work productivity, work attitude.

\begin{tabular}{|c|c|c|c|c|c|c|c|c|}
\hline \multirow[b]{2}{*}{$\begin{array}{l}\text { Outcome } \\
\text { (no. of studies) }\end{array}$} & \multicolumn{5}{|c|}{ Quality assessment } & \multicolumn{2}{|c|}{ Number of patients } & \multirow[b]{2}{*}{$\begin{array}{l}\text { Quality of } \\
\text { the evidence }\end{array}$} \\
\hline & Limitation in design & Inconsistency & Indirectness & Imprecision & $\begin{array}{l}\text { Publication } \\
\text { bias }\end{array}$ & $\mathrm{I}^{\mathrm{a}}$ & $C^{b}$ & \\
\hline Work status [22] & No serious limitation & No serious inconsistency & Indirectness & No serious imprecision & Unlikely & 1221 & 1226 & Moderate \\
\hline Work productivity [9] & Limitation in design & Inconsistency & Indirectness & No serious imprecision & Unlikely & 430 & 404 & Very low \\
\hline Work attitude [8] & Limitation in design & No serious inconsistency & Indirectness & No serious imprecision & Unlikely & 278 & 240 & Low \\
\hline
\end{tabular}

job maintenance, as outcome of the vocational rehabilitation intervention compared to the control condition (Table 3). Ten studies (45\%) showed a significant difference in favour of the intervention and another 7 (32\%) a positive trend. The methodological quality of five studies (23\%) was high, the quality of the other seventeen studies was judged as moderate or low.

The result of the meta-analysis of all studies including evaluation of the quality of the evidence are summarized in Table 4 and presented in Figure 2. When considering all twenty-two studies in the meta-analysis, we found evidence for a moderate effect of vocational rehabilitation interventions on work participation (RR 1.33; 95\% Cl 1.16-1.53). Rating down for indirectness was necessary, because there was considerable variation with regard to the content of the vocational intervention and the targeted patient populations. Although the lower border of the confidence interval was lower than 1.25 we did not rate down for 
imprecision, because the number of participants was very high. This means that we are moderately confident about this effect.

The result of the meta-analysis of five studies with high quality and low risk of bias is presented in Figure 2. It shows a large positive effect of vocational rehabilitation interventions on work participation (350 participants; RR 1.57; 95\% Cl 1.26-1.97). Only rating down of one level for indirectness was necessary.

Effects on work productivity $(n=9)$

Nine studies (three of high quality), measured changes in work productivity (Figure 3; Table 3). Of these nine studies, 6 (67\%) showed a positive trend in favor of the intervention, but the differences were small and not significant. The meta-analyses of all nine studies as well as the three high-quality studies yielded no significant differences (SMD $0.16(95 \% \mathrm{Cl}-0.06$ to 0.38$)$, respectively, 0.20 ( $95 \% \mathrm{Cl}-0.07$ to 0.47$)$. Rating down with three levels was necessary (risk of bias/inconsistency/indirectness, see Table 4), so the certainty of these results is very low.

Effects on work attitude $(n=8)$

Eight studies (three high quality) measured changes in work attitude (Figure 4; Table 3), of which two (25\%) showed a significant effect in favour of the intervention and another three (38\%) a positive trend. One study was not included in the meta-analysis because SDs were lacking [23]. When considering seven studies in the meta-analysis, we have evidence of an effect of small size (SMD 0.38; 95\% Cl 0.16-0.61) in favour of the intervention $(n=518)$. The result of the meta-analysis including evaluation of the quality of the evidence is summarized in Table 4. Rating down of two levels for risk of bias and indirectness was necessary, so we also have low certainty about this result. The result of the meta-analysis of three studies with high quality and low risk of bias is included in Figure 4 and shows an effect of moderate size (SMD 0.59; 95\% Cl 0.18-1.00) in favour of the intervention $(n=250)$.

\section{Discussion}

This systematic review summarizes data from 30 original studies in order to evaluate the characteristics and effectiveness of vocational rehabilitation interventions, that aim to improve work participation of persons with a chronic physical condition, other than back disorders. In contrast to the existing literature, we focused on interventions that apply a generic approach to enhance work participation of persons with a chronic physical condition, irrespective of the specific diagnosis. All interventions consisted of multiple treatment components, but varied widely regarding delivery characteristics and content.

Overall, $63-77 \%$ of the studies showed a positive trend on work participation, but only $25-45 \%$ of the studies showed a significant effect on work participation. Effectiveness of interventions was explored for three outcome measures of work participation: work status, work productivity and work attitude. After analyzing five trials with low risk of bias, we conclude with moderate certainty that there is a large positive effect of vocational rehabilitation interventions on work status. Analysis of both low and high quality trials $(n=22)$ yielded a moderate positive effect with low certainty (RR 1.33). We conclude with low to very low certainty that vocational rehabilitation interventions also have a moderate positive effect on work attitude (SMD $=0.59$ or 0.39 , respectively). We found no positive effects of vocational rehabilitation interventions on work productivity, although the certainty of this conclusion is very low.
All interventions in this review used a multicomponent approach; this makes it difficult to determine which component is (most) effective in enhancing work participation. Interventions that include multiple components are likely to be more effective in improving work participation than interventions consisting of a single component [10]. A multicomponent approach might be preferred because work participation is a complex process, requiring a balance between personal abilities, limitations and work demands. In persons with a chronic physical condition, the complexity of the process is increased by the unpredictable course and day-to-day variability of symptoms and, as a result, fluctuating personal physical abilities, that may interfere with the current work demands $[8,10,58]$. In addition, persons with a chronic condition have to balance work with other daily activities and life at home to be able to maintain work participation [8].

The results of this study, indicating a positive effect of the use of targeted interventions on enhancing work participation of persons with a chronic condition, are in line with systematic reviews addressing work outcomes for people with chronic back pain and mental health problems [11-13,59,60]. For people with chronic back pain, systematic reviews found evidence for a relevant effect of multidisciplinary interventions on return to work $[11,13]$ and a small effect of intense physical conditioning on reducing sick leave [12]. For persons with depression, adding a work-directed intervention to a clinical intervention reduced the number of days on sick leave; for individuals with severe mental illness, (augmented) supported employment was effective in obtaining and maintaining employment $[59,60]$.

\section{Methodological considerations}

This study provides a comprehensive and broad overview of vocational rehabilitation interventions across a wide range of chronic physical conditions, in contrast to most previous reviews that focused on a specific diagnosis. This broad overview is a potential strength, because it increases insight in the generic components of vocational rehabilitation interventions and their effects on work-related outcomes.

We performed a systematic and comprehensive search in five databases containing the most important literature from biomedical and behavioural sciences, allied health and public health. However, due to the selection of certain databases, the exclusion of uncontrolled studies, and a restriction to the English language, we may not have identified all relevant trials. In line with our study objective, we used search terms addressing chronic physical conditions, as well as physical disability. Due to this generic approach, the literature search may not have included all studies addressing vocational rehabilitation in a specific diagnosis.

The analysis and synthesis of available evidence from the 30 studies was challenging due to the diversity of interventions, the different follow-up periods, and the lack of standardized outcome measures. In addition, the small sample sizes in a number of the included studies might have caused lack of power to detect intervention effects. Comparison of outcomes at different moments in time (ranging from 3 to 104 weeks) could also have influenced our results, because the achievement of positive effects on workrelated outcomes requires a relatively long follow-up period. To improve transparency, we compared outcomes at 12 months wherever possible, and explicitly reported other follow-up periods in our results. Although included studies were heterogeneous, with respect to interventions, populations, and number of participants, we found it legitimate to rate down the level of evidence 
for the outcome work status with one level because the analysis of high-quality studies showed a heterogeneity of only $20 \%$.

Finally, we included studies from 11 different countries. Since differing systems of disability benefits have an impact on rates of absence and return to work, these systems might have affected outcomes from the various countries in different ways [61].

Although only studies with a controlled study design were included, quality assessment of the included studies showed that about $30 \%$ of the studies had a low risk of bias, whereas the other studies had a higher risk of bias. The higher risk of bias of the majority of the studies was mainly due to selection bias (participants were less likely to be representative (referred from a source or self-referred), or low percentage of agreement to participate), blinding (assessors not being blinded or study participants were aware of the research question) and data collection tools not being valid and/or reliable. Evidence of low to very low certainty is a consistent finding in studies in the domain of vocational rehabilitation. Therefore, we performed meta-analyses of only high quality studies as well as meta-analyses of both high and lower quality studies. When including only high quality trials in a meta-analysis, the effects were more pronounced.

\section{Implications for practice}

The overview of interventions in this review enables rehabilitation professionals to address work participation within rehabilitation using targeted interventions and making informed decisions about interventions. However, as a consequence of the perspective on a generic approach to improve work participation of persons with a chronic condition, and the broad variety of interventions and patient samples in the literature, the findings of this systematic review do not provide evidence which specific intervention will most effectively and efficiently benefit particular patients.

The main implications for clinical practice are twofold. First, addressing work-related problems within the rehabilitation care of persons with a chronic physical condition by means of a systematic and targeted intervention is beneficial to improve or sustain their work participation, with positive effects on finding or maintaining a job (work status) or return to work. Second, these beneficial effects seem to be generic, irrespective of the specific intervention characteristics or medical diagnosis. Notably, these generic effects were found for broad, multicomponent interventions that include individual support as one of the intervention components, whether or not combined with group sessions, and not for interventions with a single component only. Possibly, the individual support of patients may accommodate the fit between specific patient characteristics and work environment. Thus, selection of interventions should not be based on diagnoses, but professionals and persons with a chronic physical condition should select interventions that target the experienced barriers for work participation, such as physical limitations, coping with a chronic condition, or problems in the social work environment.

\section{Implications for research}

This systematic review reveals a need for further research on interventions targeting work participation in persons with a chronic physical condition to strengthen the evidence for effective interventions.

Future research should apply controlled study designs with high-quality methodology in order to improve the quality of evidence. Studies should apply a follow-up period of at least 12 months and preferably two years to examine outcomes on work participation. Primary outcome measures should be standardised, assessed and reported on all follow-up measurements. Furthermore, interventions should be adequately described to enable comparability of intervention components across studies and applicability in practice. For this, the 12-item template for intervention description and replication (TIDieR) checklist can be used [62].

Finally, future research might provide evidence or increase insight in which specific intervention will most effectively and efficiently benefit particular patients to improve work participation.

\section{Conclusion}

Vocational rehabilitation interventions consist of multiple components, and vary widely regarding content and delivery characteristics. With information from 30 controlled studies, we conclude with moderate certainty that there is a large to moderate positive effect of vocational rehabilitation interventions on work status, and with low certainty that there is a moderate to small positive effect on work attitude. We found no effect on work productivity. Most studies showed positive effects or positive trends regarding work participation, irrespective of the specific intervention characteristics and diagnosis. The risk of bias in the majority of studies was high, implying that future studies with a lower risk of bias can add to the evidence for effectiveness.

\section{Ethical approval}

This study complied with The Netherlands Code of Conduct for Scientific Practice from the Association of Universities in the Netherlands (VSNU). The requirements for authorship have been met and each author believes that the manuscript represents honest work.

\section{Disclosure statement}

No potential conflict of interest was reported by the author(s).

\section{References}

[1] Busse R, Blümel $M$, Scheller-Kreinsen D, et al. Tackling chronic disease in Europe. Strategies, interventions and challenges. World Health Organization (WHO). The European Observatory on Health Systems and Policies; 2010.

[2] Nolte E, McKee M. Caring for people with chronic conditions. A health system perspective. Maidenhead: World Health Organisation (WHO). The European Observatory on Health Systems and Policies; 2008.

[3] Detaille SI, Heerkens YF, Engels JA, et al. Common prognostic factors of work disability among employees with a chronic somatic disease: a systematic review of cohort studies. Scand J Work Environ Health. 2009;35(4):261-281.

[4] Heijmans M, van der Veer J, Spreeuwenberg P, et al. Core data on employment and income 2011 (Dutch: Kerngegevens werk en inkomen Rapportage 2011). Utrecht: Netherlands Institute for Health Services Research (NIVEL); 2011.

[5] Boot CR, Koppes LL, van den Bossche SN, et al. Relation between perceived health and sick leave in employees with a chronic illness. J Occup Rehabil. 2011;21(2):211-219. 
[6] Baanders AN, Rijken PM, Peters L. Labour participation of the chronically ill. A profile sketch. Eur J Public Health. 2002;12(2):124-130.

[7] Meulenkamp TM, Cardol M, van der Hoek LS, et al. Participation of people with physical disabilities: three-year trend and potential for improvement. Arch Phys Med Rehabil. 2013;94(5):944-950.

[8] Varekamp I, van Dijk FJ. Workplace problems and solutions for employees with chronic diseases. Occup Med (Lond). 2010;60(4):287-293.

[9] Rijken M, Spreeuwenberg P, Schippers J, et al. The importance of illness duration, age at diagnosis and the year of diagnosis for labour participation chances of people with chronic illness: results of a nationwide panel-study in The Netherlands. BMC Public Health. 2013;13:803.

[10] Vooijs M, Leensen MC, Hoving JL, et al. Disease-generic factors of work participation of workers with a chronic disease: a systematic review. Int Arch Occup Environ Health. 2015;88(8):1015-1029.

[11] Kamper SJ, Apeldoorn AT, Chiarotto A, et al. Multidisciplinary biopsychosocial rehabilitation for chronic low back pain. Cochrane Database Syst Rev. 2014;(9): CD000963.

[12] Schaafsma FG, Whelan K, van der Beek AJ, et al. Physical conditioning as part of a return to work strategy to reduce sickness absence for workers with back pain. Cochrane Database Syst Rev. 2013;(8):CD001822.

[13] Norlund A, Ropponen A, Alexanderson K. Multidisciplinary interventions: review of studies of return to work after rehabilitation for low back pain. J Rehabil Med. 2009;41(3): 115-121.

[14] Ravenek MJ, Hughes ID, Ivanovich N, et al. A systematic review of multidisciplinary outcomes in the management of chronic low back pain. Work. 2010;35(3):349-367.

[15] Grant MJ, Booth A. A typology of reviews: an analysis of 14 review types and associated methodologies. Health Info Libr J. 2009;26(2):91-108.

[16] de Croon EM, Sluiter JK, Nijssen TF, et al. Predictive factors of work disability in rheumatoid arthritis: a systematic literature review. Ann Rheum Dis. 2004;63(11):1362-1367.

[17] Haafkens J, Moerman C, Schuring M, et al. Searching bibliographic databases for literature on chronic disease and work participation. Occup Med (Lond). 2006;56(1):39-45.

[18] Higgins JPT, Green SE. Cochrane Handbook for Systematic Reviews of Interventions Version 5.1.0: The Cochrane Collaboration; 2011 [cited 2020 Jun 30]. Available from: http:/www.cochrane-handbook.org

[19] Armijo-Olivo S, Stiles CR, Hagen NA, et al. Assessment of study quality for systematic reviews: a comparison of the Cochrane Collaboration Risk of Bias Tool and the Effective Public Health Practice Project Quality Assessment Tool: methodological research. J Eval Clin Pract. 2012;18(1): 12-18.

[20] The Nordic Cochrane Centre. Review Manager (RevMan). [Computer program]. Version 5.3. Copenhagen: The Cochrane Collaboration; 2011.

[21] Guyatt GH, Oxman AD, Kunz R, GRADE Working Group, et al. GRADE guidelines: 7. Rating the quality of evidenceinconsistency. J Clin Epidemiol. 2011;64(12):1294-1302.

[22] Hutting N, Staal JB, Engels JA, et al. Nijhuis-van der Sanden MW. Effect evaluation of a self-management programme for employees with complaints of the arm, neck or shoulder: a randomised controlled trial. Occup Environ Med. 2015;72(12):852-861.

[23] Martin DJ, Chernoff RA, Buitron M, et al. Helping people with HIV/AIDS return to work: a randomized clinical trial. Rehabil Psychol. 2012;57(4):280-289.

[24] Cohen J. Statistical power analysis for the behavioral sciences. 2nd ed. Hillsdale (NJ): Lawrence Erlbaum Associates; 1988.

[25] Guyatt G, Oxman AD, Akl EA, et al. GRADE guidelines: 1. Introduction-GRADE evidence profiles and summary of findings tables. J Clin Epidemiol. 2011;64(4):383-394.

[26] Guyatt GH, Oxman AD, Kunz R, et al. GRADE guidelines 6. Rating the quality of evidence-imprecision. J Clin Epidemiol. 2011;64(12):1283-1293.

[27] Guyatt GH, Oxman AD, Kunz R, GRADE Working Group, et al. GRADE guidelines: rating the quality of evidenceindirectness. J Clin Epidemiol. 2011;64(12):1303-1310.

[28] Brożek JL, Akl EA, Compalati E, GRADE Working Group, et al. Grading quality of evidence and strength of recommendations in clinical practice guidelines part 3 of 3 . The GRADE approach to developing recommendations. Allergy. 2011;66(5):588-595.

[29] Guyatt GH, Oxman AD, Montori V, et al. GRADE guidelines: 5. Rating the quality of evidence-publication bias. J Clin Epidemiol. 2011;64(12):1277-1282.

[30] Allaire SH, Li W, LaValley MP. Reduction of job loss in persons with rheumatic diseases receiving vocational rehabilitation: a randomized controlled trial. Arthritis Rheum. 2003; 48(11):3212-3218.

[31] Anderson B, Strand LI, Raheim M. The effect of long-term body awareness training succeeding a multimodal cognitive behavior program for patients with widespread pain. J Musculoskel Pain. 2007;15(3):19-29.

[32] Brattberg G. Internet-based rehabilitation for individuals with chronic pain and burnout: a randomized trial. Int J Rehabil Res. 2006;29(3):221-227.

[33] Cheng ASK, Hung LK. Randomized controlled trial of workplace-based rehabilitation for work-related rotator cuff disorder. J Occup Rehabil. 2007;17(3):487-503.

[34] de Buck PD, Le Cessie S, van den Hout WB, et al. Randomized comparison of a multidisciplinary job-retention vocational rehabilitation program with usual outpatient care in patients with chronic arthritis at risk for job loss. Arthritis Rheum. 2005;53(5):682-690.

[35] Detaille S, Heerkens $Y$, Engels J, et al. Effect evaluation of a self-management program for Dutch workers with a chronic somatic disease: a randomized controlled trial. J Occup Rehabil. 2013;23(2):189-199.

[36] Feuerstein $M$, Callan-Harris $S$, Hickey $P$, et al. Multidisciplinary rehabilitation of chronic work-related upper extremity disorders. Long-term effects. J Occup Med. 1993;35(4):396-403.

[37] Haffey W, Abrams D. Employment outcomes for participants in a brain injury work reentry program: preliminary findings. J Head Trauma Rehabil. 1991;6(3):24-34.

[38] Ipsen C, Ravesloot C, Arnold N, et al. Working well with a disability: health promotion as a means to employment. Rehabil Psychol. 2012;57(3):187-195.

[39] Kendall NAS, Thompson BF. A pilot program for dealing with the comorbidity of chronic pain and long-term unemployment. J Occup Rehabil. 1998;8(1):5-26.

[40] Li EJ, Li-Tsang CW, Lam CS, et al. The effect of a training on work readiness program for workers with 
musculoskeletal injuries: a randomized control trial (RCT) study. J Occup Rehabil. 2006;16(4):529-541.

[41] Li-Tsang CWP, Li EJQ, Lam CS, et al. The effect of a job placement and support program for workers with musculoskeletal injuries: a randomized control trial (RCT) study. J Occup Rehabil. 2008;18(3):299-306.

[42] Macedo AM, Oakley SP, Panayi GS, et al. Functional and work outcomes improve in patients with rheumatoid arthritis who receive targeted, comprehensive occupational therapy. Arthritis Rheum. 2009;61(11):1522-1530.

[43] Marhold C, Linton SJ, Melin L. A cognitive-behavioral return-to-work program: effects on pain patients with a history of long-term versus short-term sick leave. Pain. 2001; 91(1-2):155-163.

[44] Marnetoft SU, Selander J. Multidisciplinary vocational rehabilitation focusing on work training and case management for unemployed sick-listed people. Int J Rehabil Res. 2000;23(4):271-279.

[45] Niemeier JP, Degrace SM, Farrar LF, et al. Effectiveness of a comprehensive, manualized intervention for improving productivity and employability following brain injury. J Vocat Rehabil. 2010;33(3):167-179.

[46] Ntsiea MV, Van Aswegen $\mathrm{H}$, Lord S, et al. The effect of a workplace intervention programme on return to work after stroke: a randomised controlled trial. Clin Rehabil. 2015; 29(7):663-673.

[47] Ottomanelli L, Goetz LL, Suris A, et al. Effectiveness of supported employment for veterans with spinal cord injuries: results from a randomized multisite study. Arch Phys Med Rehabil. 2012;93(5):740-747.

[48] Salazar AM, Warden DL, Schwab K, et al. Cognitive rehabilitation for traumatic brain injury: a randomized trial. Defense and Veterans Head Injury Program (DVHIP) Study Group. J Am Med Assoc. 2000;283(23):3075-3081.

[49] Skouen JS, Grasdal A, Haldorsen EM. Return to work after comparing outpatient multidisciplinary treatment programs versus treatment in general practice for patients with chronic widespread pain. Eur J Pain. 2006;10(2):145-152.

[50] Sullivan MJ, Adams H, Rhodenizer T, et al. A psychosocial risk factor-targeted intervention for the prevention of chronic pain and disability following whiplash injury. Phys Ther. 2006;86(1):8-18.

[51] Trexler LE, Parrott DR, Malec JF. Replication of a prospective randomized controlled trial of resource facilitation to improve return to work and school after brain injury. Arch Phys Med Rehabil. 2016;97(2):204-210.

[52] Varekamp I, Verbeek $\mathrm{JH}$, de Boer A, et al. Effect of job maintenance training program for employees with chronic disease - a randomized controlled trial on self-efficacy, job satisfaction, and fatigue. Scand J Work Environ Health. 2011;37(4):288-297.

[53] van Vilsteren M, Boot CR, Twisk JW, et al. Effectiveness of an integrated care intervention on supervisor support and work functioning of workers with rheumatoid arthritis. Disabil Rehabil. 2017;39(4):354-359.

[54] Meyer K, Fransen J, Huwiler $\mathrm{H}$, et al. Feasibility and results of a randomised pilot-study of a work rehabilitation programme. BMR. 2005;18(3-4):67-78.

[55] Hammond A, O'Brien R, Woodbridge $S$, et al. Job retention vocational rehabilitation for employed people with inflammatory arthritis (WORK-IA): a feasibility randomized controlled trial. BMC Musculoskelet Disord. 2017;18(1):315.

[56] Keysor JJ, LaValley MP, Brown C, et al. Efficacy of a work disability prevention program for people with rheumatic and musculoskeletal conditions: a single-blind parallel-arm randomized controlled trial. Arthritis Care Res (Hoboken). 2018;70(7):1022-1029.

[57] Dorstyn D, Roberts R, Murphy G, et al. Work and SCl: a pilot randomized controlled study of an online resource for job-seekers with spinal cord dysfunction. Spinal Cord. 2019; 57(3):221-228.

[58] de Ridder D, Geenen R, Kuijer R, et al. Psychological adjustment to chronic disease. Lancet. 2008;372(9634):246-255.

[59] Nieuwenhuijsen K, Faber B, Verbeek JH, et al. Interventions to improve return to work in depressed people. Cochrane Database Syst Rev. 2014;(12):CD006237.

[60] Suijkerbuijk YB, Schaafsma FG, van Mechelen JC, et al. Interventions for obtaining and maintaining employment in adults with severe mental illness, a network meta-analysis. Cochrane Database Syst Rev. 2017;(9):CD011867.

[61] Anema JR, Schellart AJ, Cassidy JD, et al. Can cross country differences in return-to-work after chronic occupational back pain be explained? An exploratory analysis on disability policies in a six country cohort study. J Occup Rehabil. 2009;19(4):419-426.

[62] Hoffmann TC, Glasziou PP, Boutron I, et al. Better reporting of interventions: template for intervention description and replication (TIDieR) checklist and guide. BMJ. 2014;348: g1687. 